\title{
Probing Structure-Property Relationship of Active Metal Nanoparticles on Mesoporous Silica Sorbent
}

\author{
Prashant Kumar, ${ }^{1}$ Jong Seok Jeong, ${ }^{1}$ Bahman Elyassi, ${ }^{1}$ Nafiseh Rajabbeigi, ${ }^{1}$ Michael Tsapatsis, ${ }^{1}$ \\ K. Andre Mkhoyan ${ }^{1}$ \\ ${ }^{1}$ Department of Chemical Engineering \& Materials Science, University of Minnesota, Minneapolis, MN
}

Zinc-based adsorbents currently in use for $\mathrm{H}_{2} \mathrm{~S}$ removal from tail gas in the oil and gas industry have limited regenerability and reduced performance over multiple cycles [1,2]. Spatially well-distributed metal nanoparticles in mesoporous substrates can be effective in achieving better performance over multiple adsorption and regeneration cycles [3,4]. One of the critical aspects of understanding the functionality of these metal nanoparticles incorporated into mesoporous substrates is determination of the nanoparticle distribution throughout the substrate.

Using analytical scanning transmission electron microscopy (STEM), we studied spatial distribution of these nanoparticles. We examined freshly prepared amorphous mesoporous $\mathrm{SiO}_{\mathrm{x}}$ framework (known as SBA-15), Cu- and Zn- incorporated SBA-15 (Cu-Zn-SBA-15), and sulfidated Cu-Zn-SBA-15. TEM samples were prepared by microtoming 60-100 nm sections containing the powder sample embedded in epoxy resin. Elemental mapping was performed by collecting spatially resolved STEM-EDS spectrum images in FEI Tecnai F30 STEM equipped with EDAX ${ }^{\mathrm{TM}}$ EDX spectrometer to identify the presence and distribution of $\mathrm{Cu}$ and $\mathrm{Zn}$ in the framework (Figure 1). Additionally, high-resolution HAADF-STEM images were obtained, using FEI Titan G2 60-300 S/TEM operated at $300 \mathrm{kV}$, to determine location of the $\mathrm{Cu}$ and $\mathrm{Zn}$ particles relative to mesopores of SBA-15 (Figure 2).

Presence of $\mathrm{Cu}$ and $\mathrm{Zn}$ observed in EDS elemental maps supports a previous Ar adsorption-desorption isotherm study, which indicated a median pore size reduction from $7.9 \mathrm{~nm}$ to $7.6 \mathrm{~nm}$ due to the incorporation of mixed metal nanoparticles. HAADF-STEM images of samples in two perpendicular orientations revealed that: (i) $\mathrm{Cu}$ and $\mathrm{Zn}$ nanoparticles are $<3 \mathrm{~nm}$ in diameter and (ii) they are uniformly distributed throughout the SBA-15 mesopores. Additionally, we did not observe aggregation of $\mathrm{Cu}$ and Zn nanoparticles after sulfidation in our HAADF-STEM images, which was further corroborated by the high adsorption capacity of $\mathrm{H}_{2} \mathrm{~S}$ after several cycles of adsorption-regeneration. Through focal HAADF-STEM image series also revealed that the $\mathrm{Cu}$ and $\mathrm{Zn}$ particles are located on the walls of mesopores [5].

\section{References:}

[1] P. Kumar et al, Microporous Mesoporous Materials 146 (2011) 127-133.

[2] M. Behl et al, Nature Nanotechnology 7 (2012) 810-815.

[3] G. Prieto et al, Nature Materials 12 (2013) 34-39.

[4] B. Elyassi et al, Microporous Mesoporous Materials (accepted).

[5] The authors acknowledge funding by the MRSEC Program of the National Science Foundation under Award Number DMR-0819885. 

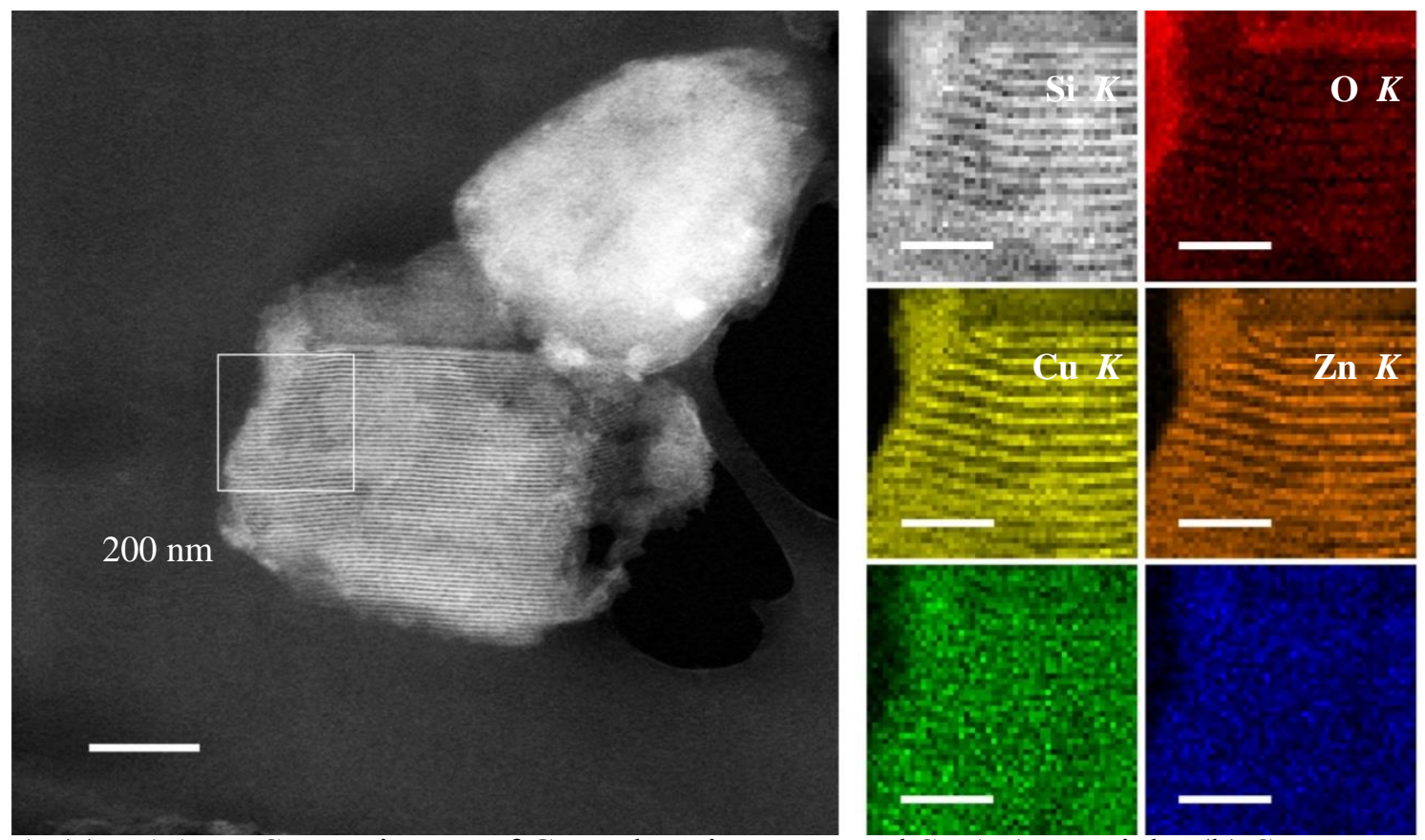

Figure 1. (a) HAADF-STEM image of $\mathrm{Cu}$ and $\mathrm{Zn}$ incorporated SBA-15 particle. (b) STEM-EDS elemental map of carbon, silicon, oxygen, copper and zinc (scale bar $100 \mathrm{~nm}$ ) from section of the particle shown as a box in (a). Silicon and oxygen form the mesoporous SBA-15 substrate and $\mathrm{Cu} / \mathrm{Zn}$ metal particles are distributed within the SBA-15 substrate.
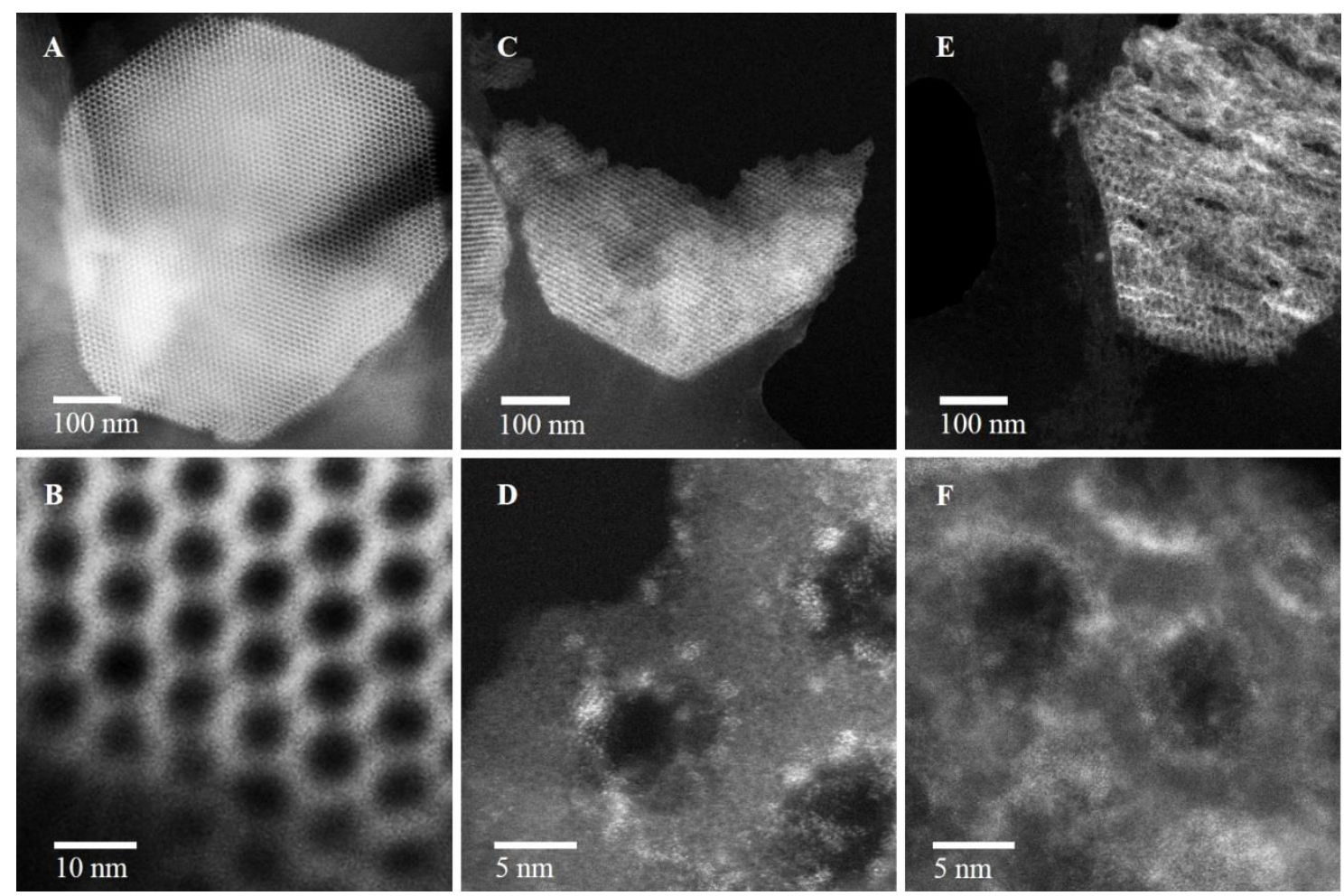

Figure 2. HAADF-STEM images of SBA-15 particles (a,b) without metal treatment; (c,d) after $\mathrm{Cu} / \mathrm{Zn}$ incorporation; (e,f) after sulfidation of $\mathrm{Cu} / \mathrm{Zn}$ incorporated samples. 